\title{
ANALISIS KERJA SISTEM REFRIGERASI MEJA PENJAJA IKAN
}

\author{
PERFORMANCE ANALISYS OF REFRIGERATION SYSTEM FISH DISPLAY TABLE
}

\author{
Imam Taukhid, Donal Daniel dan B. Realino S. \\ Pusat Pengkajian dan Perekayasaan Teknologi Kelautan dan Perikanan, Balitbang KP \\ Jl. Pasir Putih 1 Ancol Timur, Jakarta 14430 \\ E-mail: imam_t@kkp.go.id
}

Diterima tanggal: 29 September 2014, diterima setelah perbaikan: 15 November 2014, disetujui tanggal: 28 November 2014

\begin{abstract}
ABSTRAK
Penjual ikan di pasar-pasar tradisional masih mengalami kendala dalam menerapkan teknik pengesan. Salah satu solusi untuk mengatasi kendala tersebut adalah dengan menerapkan teknologi refrigerasi. Teknologi refrigerasi yaitu suatu teknologi yang dapat digunakan untuk menyerap panas dari ikan dengan tujuan untuk menurunkan temperatur sesuai dengan yang diinginkan. Pada makalah ini dilakukan pengujian dengan menggunakan meja penjaja ikan yang telah terintegrasi dengan sistem refrigerasi. Peralatan sistem refrigerasi yang digunakan yaitu kompresor, kondensor, evaporator, pipa kapiler dan refrigerant R134a. Hasil analisis pengujian sistem refrigerasi menunjukkan nilai maksimal Coefficient of Performance (COP) sebesar 5, efesiensi $99 \%$ dan kebutuhan listrik rata-rata sebesar 350 Watt.
\end{abstract}

Kata kunci: pasar, tradisional, meja penjaja, refrigerasi, COP.

\begin{abstract}
Fish sellers in the traditional market's are still have problems in apply the technique perceiver. One of the solutions to overcome these obstacles is to apply the technology of refrigeration. The refrigeration technology is very useful to absorb heat from fish's body with the aim to have a suitable temperature. This paper aim to the performance work refrigerator technology by using fish display table that had been installed integrated refrigeration system. An integrated compressor, condenser, caliper tube, evaporator and R134a refrigerant have been used. The result found that the integrated refrigeration system, the value coefficient of performance (COP) is 5, with 99\% efficiency and 350 watt of electricity.
\end{abstract}

Keywords: market, traditional, display table, refrigeration, COP.

\section{PENDAHULUAN}

Ada tiga cara dalam mempertahankan kesegaran ikan yaitu dengan es (pengesan), dengan udara dingin (refrigerasi) dan dengan air dingin (chiller) (Ilyas, 1983). Cara umum yang digunakan oleh penjual ikan adalah dengan teknik pengesan, akan tetapi penjual ikan tidak menerapkan teknik pengesan yang sesuai prosedur sehingga mutu ikan terus mengalami kemunduran. Proses kemunduran mutu ikan pada dasarnya dapat dilihat dari dua sudut pandang yaitu kesegaran dan kebusukan (Wibowo dan Yunizal,1998).
Penggunaan wadah terbuka sangat mempengaruhi kualitas ikan yang dijual. Indonesia merupakan wilayah tropis, yang menyebabkan bakteri cepat berkembang. Penanganan ikan di sebagian besar Tempat Pelelangan Ikan (TPI) atau Pelabuhan Pendaratan Ikan (PPI) pasca turun dari kapal sangat tidak higienis. Pembeli dan penjual ikan hanya menyimpan ikan di bak, jika bak sudah tidak muat, maka ikan-ikan tersebut hanya diletakkan di lantai tanpa alas apapun, sehingga mutu ikan terus mengalami penurunan. Hal tersebut menunjukan bahwa penanganan ikan setelah penangkapan belum dilakukan dengan baik (Irianto dan Soesilo, 2007). 
Masalah utama yang dihadapi dalam penanganan ikan adalah penjual ikan menggunakan bak terbuka untuk menjajakan ikan jualannya, sehingga mengakibatkan penurunan mutu ikan yang cepat akibat penanganan yang tidak tepat (Suherman dan Gunawan, 1999).

Penanganan ikan yang tidak baik juga terjadi di pasar ikan tradisional, dimana kondisi pasar ikan identik dengan becek dan tidak higienis. Hal ini terjadi oleh karena pengetahuan nelayan tentang tata cara penanganan ikan dari saat menangkap sampai di pendaratan ikan pada umumnya masih rendah. Perbandingan antara jumlah ikan dan es dalam tempat penyimpanan yang tidak sesuai menyebabkan masih tingginya kerusakan produk perikanan tangkap (Sjarif, Suwardiyono dan Syahasta, 2010). Padahal, sebagian besar produk ikan segar tujuan ekspor berasal dari nelayan tradisional yang menggunakan kapal kayu dan es sebagai media pengawetan ikan (Daniel, 2011).

Penjual ikan di pasar tradisional menggunakan air yang dicampur dengan es curah (pengesan) untuk mempertahankan ikan jualannya. Penerapan teknik pengesan yang dilkakukan oleh penjual ikan juga tidak sesuai dengan prosedur, terutama perbandingan antara banyaknya ikan dengan banyaknya es yang digunakan. Seharusnya prosedur teknik pengesan dalam penanganan dan penyimpanan ikan hasil tangkap dengan es yang ideal adalah 1:1 (Pusat Pengembangan dan Pemberdayaan Pendidik dan Tenaga Kependidikan Pertanian, 2010).

Untuk mengatasi hal tersebut, dapat diterapkan teknologi refrigerasi. Teknologi ini memudahkan para penjual ikan di pasar tradisonal tanpa harus memperhitungkan jumlah ikan dan jumlah es, cukup mengatur temperatur ruang penyimpanan ikan sesuai dengan yang diinginkan. Penggunaan teknologi refrigerasi sudah banyak digunakan seperti: cold storage, kulkas (refrigerator), freezer, dan lain lain (Dossat, 1961).

Teknik refrigerasi adalah suatu teknik untuk menyerap panas dari suatu benda untuk menurunkan temperatur sesuai dengan yang diinginkan. Tujuannya adalah untuk menghambat laju pertumbuhan bakteri penyebab kemunduran mutu ikan, sehingga menjaga ikan tetap segar. Umumnya, sistem refrigerasi terdiri dari kompresor, kondensor, katup expansi dan evaporator (Tampubolon dan Samosir, 2005). Kompresor merupakan komponen utama dalam sistem refrigerasi yang berfungsi mengkompresikan refrigerant. Refrigerant merupakan zat cair (freon) terdapat pada sistem refrigerasi yang berfungsi menyerap panas dari benda atau udara yang akan didinginkan. Coefficient of performance (COP) adalah suatu indikator yang digunakan untuk menilai efisiensi energi sistem refrigerasi (Setyoko, Darmanto, dan Rahmat, 2007).

Dalam penelitian skala laboratorium, untuk mengetahui performa sistem refrigerasi dengan menggunakan refrigerant $\mathrm{R} 134 \mathrm{a}$, lampu sebagai beban, didapat nilai COP sebesar 2,64 dalam waktu 30 menit (Anwar, 2010). Analisis kompresi uap sistem refrigerasi dengan mengunakan dua jenis refrigerant R22 dan R134a didapat nilai COP R22 3,25 dan COP R134a 3,35 (Chandrasekharan, 2014). Hasil penelitian Sattar, Saidur dan Masjuki (2007) yang menggunakan sistem pendingin freezer 80 liter dengan refrigerant R134a menunjukkan performa yang baik terhadap kondensor, evaporator dan COP, serta dapat mengurangi kebutuhan energi listrik sebesar 3\%. Hasil penelitian yang dilakukan oleh Yunianto (2005) menyatakan bahwa peningkatan nilai COP dipengaruhi oleh naiknya nilai evaporator.

Verma, Satsangi dan Chaturani (2013) menyatakan bahwa dengan menggunakan refrigerant R134a sebagai alternatif refrigerant untuk refrigerasi pada Air conditioner (AC) mobil sangat aman digunakan dan ramah lingkungan. Pada penelitian eksperimental yang dilakukan oleh Tiwari dan Gupta (2011), penggunaan refrigerant lokal R404a dan R134a menunjukkan bahwa refrigerant tersebut sangat ramah lingkungan dan tidak merusak lapisan ozone. Dari hasil pengujian sistem refrigerasi yang dilakukan oleh Jain, Kachhwaha dan Mishra (2011) dengan berbagai macam refrigerant (R22, R134a, R410a, R407c dan M20) untuk mengetahui performa sistem refrigerasi, diperoleh hasil bahwa refrigerant $\mathrm{R} 407 \mathrm{c}$ dapat menggantikan refrigerant terdahulunya. Selanjutnya, jika ingin mendapatkan biaya operasional dan perawatan sistem refrigerasi yang paling murah disarankan menggunakan refrigerant $\mathrm{R} 22$.

Untuk meningkatkan COP dapat juga dilakukan dengan cara melilitkan pipa kapiler di line suction 
(Handoyo dan Lukito, 2002). Hasil pengujian Gulati dan Gupta (2011) dengan berbagai ukuran pipa kapiler (1,2-2,4 mm) dan beberapa jenis refrigerant (R22, R134a dan R404a), menunjukkan bahwa tidak ada pengaruh energi kinetik terhadap konversi energi, dan faktor gesekan pipa kapiler semua jenis memberikan hasil yang optimal dalam semua kondisi. Akan tetapi, dengan memodifikasi pipa kapiler, dapat memudahkan perbaikan pada saat pengisian refrigerant dan perbaikan sistem refrigerasi (Raut dan Wankhede, 2011).

Tujuan dari penelitian ini adalah untuk mengetahui performa sistem (COP) refrigerasi meja penjaja ikan, sehingga dapat menjaga mutu ikan yang dijual di Pasar Tradisional.

\section{BAHAN DAN METODE}

Penelitian ini menguji sistem refrigerasi pada meja penjaja ikan yang dirancang dan dibuat oleh penulis (Gambar 1) dengan menggunakan fluida refrigerant R134a. Bagian-bagian sistem refrigerasi dari meja penjaja ikan tersebut terdiri dari: kompresor, kondensor, pipa kalpiler, evaporator dan R134a.

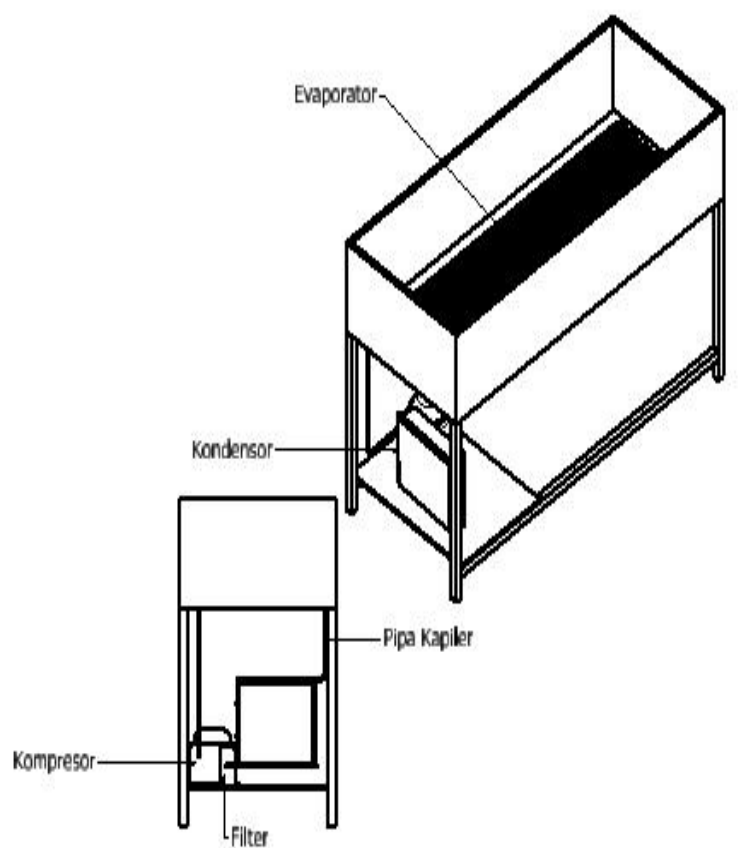

Gambar 1. Sketsa meja penjaja ikan dengan sistem refrigerasi

Figure 1. Sketch of refrigerator system sale fish display table

Sumber: Dokumentasi pribadi
Pada pengujian dilakukan pengukuran suhu, arus listrik dan tekanan dengan metode laboratorium, dimana dilakukan pengukuran suhu pada kondensor dan evaporator dengan menggunakan thermometer manual dan thermometer digital, pengukuran tekanan dengan menggunakan manometer, sedangkan untuk mengukur arus listrik digunakan ampere meter. Pengujian ini dilakukan di gedung Balitbang KP dengan waktu pengujian 30 menit tanpa beban (Gambar 2).

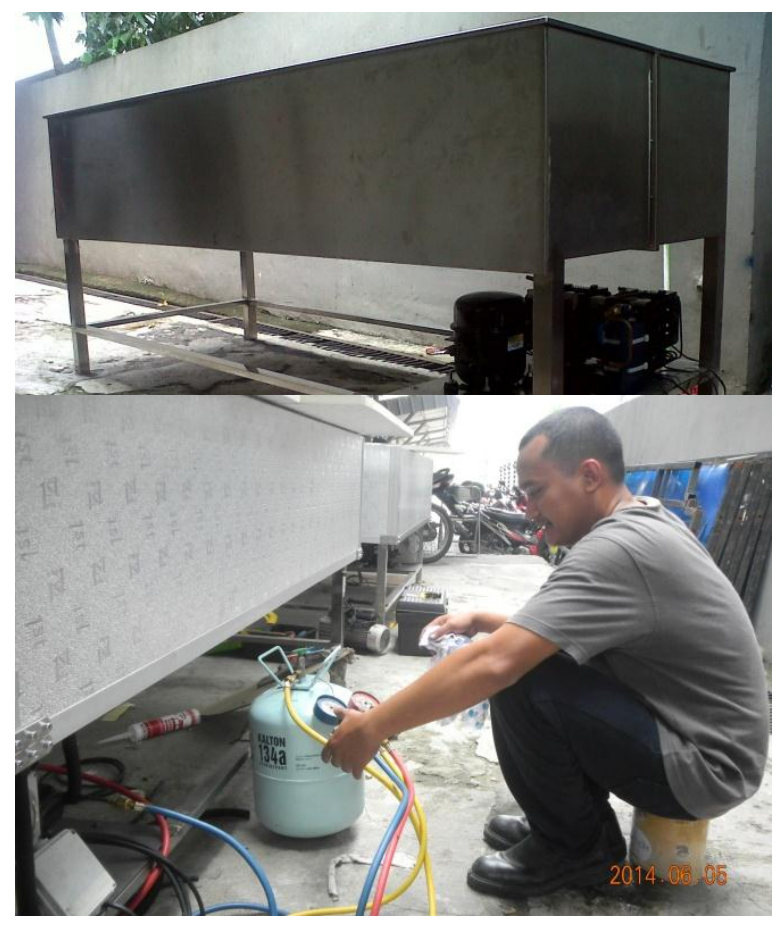

Gambar 2. Proses pengujian meja penjaja ikan Figure 2. Testing of sale fish display table Sumber: Dokumentasi pribadi

Untuk menganalisis data hasil pengamatan, digunakan persamaan-persamaan sebagai berikut :

$\circ$ Daya = V.I (Watt)

- Laju aliran refrigerant :

$\mathrm{M}_{\text {ref }}=\mathrm{Nc} / \mathrm{h}_{2}-\mathrm{h}_{1}$

dimana :

$\mathrm{Nc}=$ daya kompressi

$=\eta_{\text {compresor }} \mathrm{x}$ daya kompresor

$\eta=$ dari data spesifikasi kompresor 0.7

$\mathrm{h}_{1}$ dan $\mathrm{h}_{2}=$ nilai enthalphi refrigerant $\mathrm{R} 134 \mathrm{a}$

- Laju aliran kalor yang dilepas kondensor:

$\mathrm{Q}_{\mathrm{k}}=\mathrm{m}_{\text {ref }}\left(\mathrm{h}_{2}-\mathrm{h}_{3}\right) \mathrm{kW}$

- Laju aliran kalor yang di serap evaporator

$\mathrm{Q}_{\mathrm{e}}=\mathrm{m}_{\text {ref }}\left(\mathrm{h}_{1}-\mathrm{h}_{4}\right) \mathrm{kW}$

- Coefisien Of Performance (COP)

$\mathrm{Cop}_{R}=\frac{\text { Cooling Effect }=Q \mathrm{Ql}}{\text { Work Input }=W_{\text {net In }}}$ 
$\mathrm{Cop}_{H P}=\frac{\text { Heating } E f f e c k=Q H}{\text { Work } \text { Input }=W_{\text {Net In }}}$

- Efesiensi dengan menggunakan : $\eta=\operatorname{Cop}_{R} / \operatorname{Cop}_{H P}$

- Jumlah kebutuhan es yang di perlukan untuk mempertahankan ikan $\mathrm{Q}=m\left(\mathrm{~T}_{1}-\mathrm{T}_{2}\right) C_{p}$

Dimana Q adalah jumlah panas yang harus dihilangkan dari ikan (Wibowo et al.,1998).

$$
\begin{aligned}
m= & \text { berat ikan }(\mathrm{kg}) \\
\mathrm{T}_{1}= & \text { suhu awal ikan }\left({ }^{\circ} \mathrm{C}\right) \\
\mathrm{T}_{2}= & \text { suhu akhir ikan }\left({ }^{\circ} \mathrm{C}\right) \\
\mathrm{C}_{\mathrm{p}}= & \text { panas spesifik ikan }(0,84 \\
& \left.\mathrm{kkal} /{ }^{\circ} \mathrm{C} / \mathrm{kg}\right) .
\end{aligned}
$$

\section{HASIL DAN PEMBAHASAN}

Bardasarkan hasil pengujian, diperoleh bahwa dalam waktu 0-2 menit tekanan masih sangat tinggi dan temperatur ruangan sama dengan temperatur udara luar, akan tetapi dalam waktu 2630 menit tekanan dan temperatur di peroleh nilai yang signifikan yaitu temperatur $-15^{\circ} \mathrm{C}$ sedangkan tekanan 2 Psi. Data suhu, arus dan waktu, hasil pengamatan disajikan pada Tabel 1.

Tabel 1. Data pengamatan

Table 1. Observations data

\begin{tabular}{ccccccc}
\hline \multirow{2}{*}{ No } & \multicolumn{2}{c}{$\begin{array}{c}\text { PRESSURE } \\
\text { (Psi) }\end{array}$} & \multicolumn{2}{c}{ TEMP $\left({ }^{\mathbf{} C}\right)$} & Arus & Waktu \\
\cline { 2 - 7 } & Low & High & Kond & Evap & (Amp) & (Menit) \\
\hline 1 & 80 & 160 & 36 & 27 & 3.3 & 0 \\
\hline 2 & 20 & 145 & 34 & 20 & 2.2 & 2 \\
\hline 3 & 12 & 140 & 35 & 11 & 2.2 & 4 \\
\hline 4 & 10 & 130 & 36 & 0 & 2.2 & 6 \\
\hline 5 & 9 & 130 & 36 & -3 & 2.2 & 8 \\
\hline 6 & 9 & 130 & 35 & -5 & 2.1 & 10 \\
\hline 7 & 9 & 130 & 35 & -7 & 2.1 & 12 \\
\hline 8 & 9 & 130 & 35 & -8 & 2.1 & 14 \\
\hline 9 & 9 & 130 & 35 & -9 & 2.1 & 16 \\
\hline 10 & 9 & 130 & 35 & -10 & 2.1 & 18 \\
\hline 11 & 9 & 130 & 35 & -11 & 2.1 & 20 \\
\hline 12 & 4 & 116 & 34 & -12 & 2 & 22 \\
\hline 13 & 4 & 116 & 34 & -13 & 2 & 24 \\
\hline 14 & 2 & 116 & 34 & -14 & 2 & 26 \\
\hline 15 & 2 & 116 & 34 & -15 & 2 & 30 \\
\hline Sumber: Hasil pengujian & & & & \\
\hline
\end{tabular}

Sumber: Hasil pengujian
Dari hasil pengujian sistem refrigerasi meja penjaja ikan ini, dapat diketahui nilai kebutuhan daya, laju aliran refrigerant, kalor yang dilepas kondensor, kalor yang di serap evaporator, COP dan efesiensi.

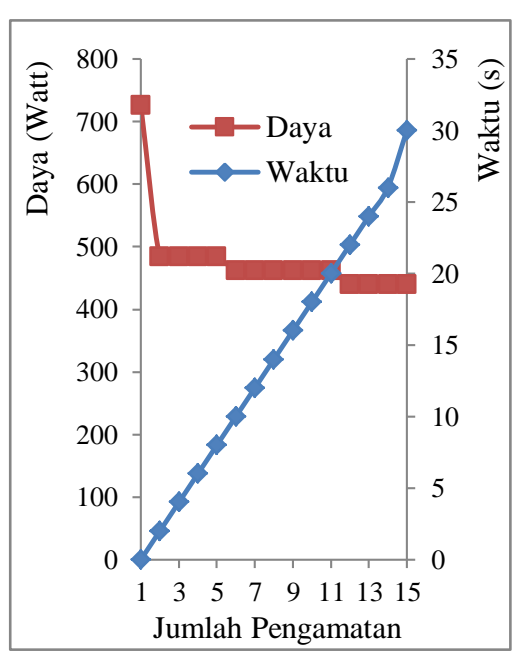

Grafik 1. Daya kompresor terhadap waktu Chart 1. Compressor power vs time Sumber: Hasil pengolahan data

Dari hasil pengujian dapat diketahui bahwa daya mengalami penurunan berbanding terbalik dengan waktu, dimana jika waktu semakin lama semakin naik maka daya semakin lama semakin menurun (Grafik 1). Hal tersebut terjadi karena kompresor yang digunakan mempunyai kapasitas daya sebesar 1 horse power $(\mathrm{HP})$ dimana $1 \mathrm{HP}=745$ Watt.

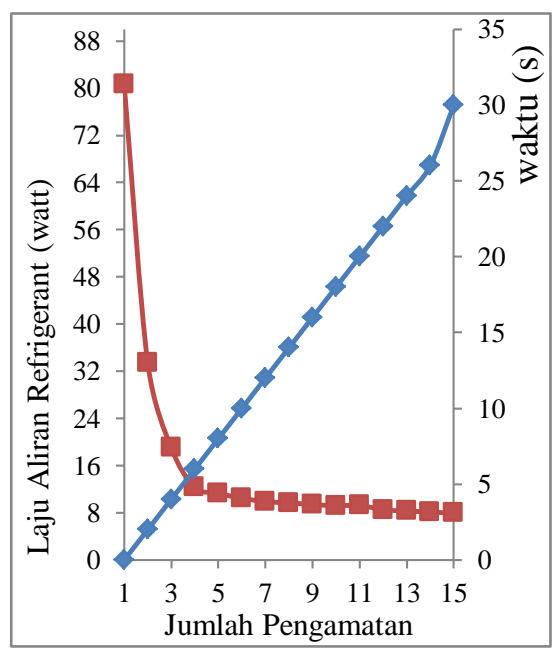

Grafik 2. Laju aliran refrigerant terhadap waktu Chart 2. Refrigerant flow rate vs time Sumber: Hasil pengolahan data 
Dari grafik 2 terlihat bahwa laju aliran refrigerant berbanding terbalik terhadap waktu, dimana faktor utama yang mempengaruhi penurunan dari laju aliran refrigerant adalah daya kompresor.

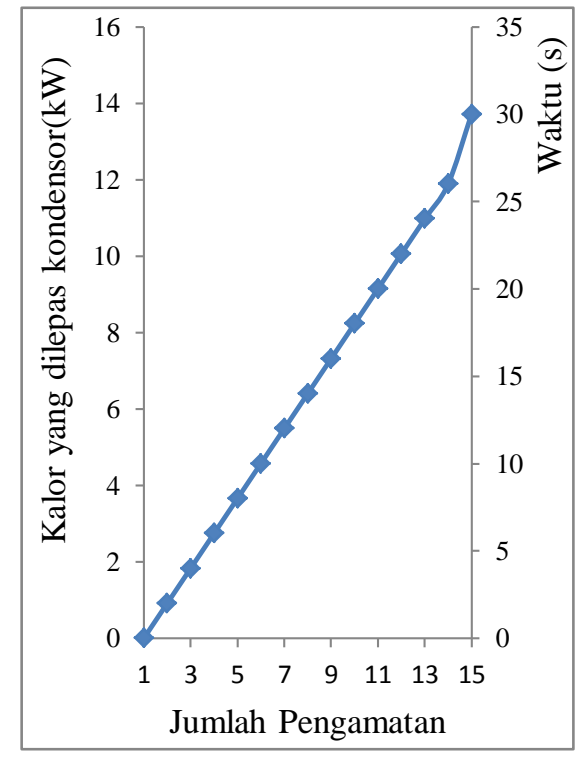

Grafik 3. Laju aliran kalor yang dilepas kondensor terhadap waktu

Chart 3. Flow rate condenser heat removed vs time

Sumber: Hasil pengolahan data

Grafik 3 memperlihatkan bahwa laju aliran kalor yang di lepas kondensor berbanding terbalik dengan waktu, akan tetapi berbanding lurus dengan laju aliran refrigerant. Faktor utama yang mempengaruhi besarnya kalor yang dilepas kondensor adalah laju aliran refrigerant.

Grafik 4 memperlihatkan bahwa laju aliran kalor yang diserap evaporator berbanding terbalik dengan waktu, akan tetapi berbanding lurus dengan laju aliran kalor yang dilepas kondensor. Faktor utama yang mempengaruhi besarnya kalor yang diserap evaporator adalah laju aliran kalor yang dilepas kondensor.

Grafik 5 memperlihatkan perbandingan nilai $\mathrm{COP}_{R}$ dan $\mathrm{COP}_{H P}$, dimana penurunan nilai $\mathrm{COP}$ berbanding lurus tetapi berbanding terbalik terhadap waktu. Penurunan COP dipengaruhi oleh laju aliran kalor yang diserap evaporator terhadap komsumsi daya yang dibutuhkan oleh kompresor, dimana lama kerja kompresor mempengaruhi kebutuhan komsumsi dayanya. Berdasarkan hasil pengujian yang telah dilakukan, diketahui bahwa nilai COP sistem refrigerasi meja penjaja ikan masih berada dalam standar COP yang disarankan oleh Badan Standardisasi Nasional (SNI). Dimana nilai COP sistem refrigerasi menurut SNI berkisar antara 2,7 sampai dengan 6,5.

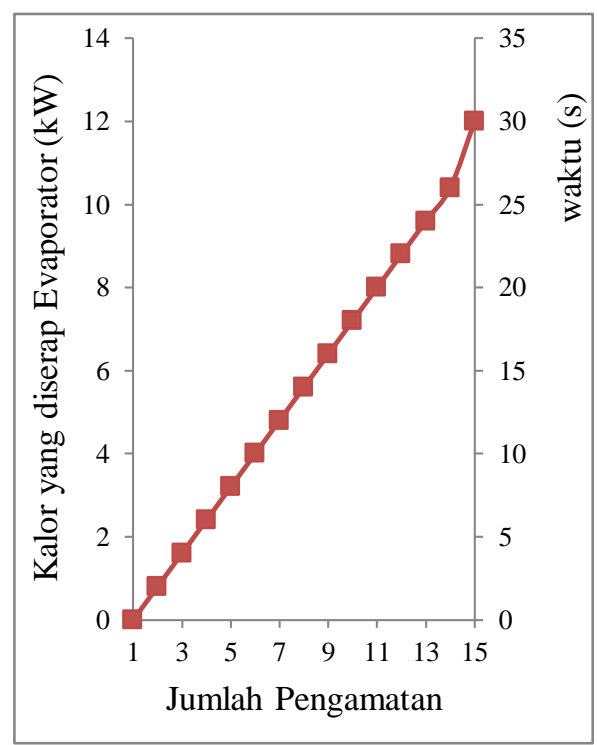

Grafik 4. Laju aliran kalor yang diserap evaporator terhadap waktu.

Chart 4. Flow rate evaporator heat absorbed vs time

Sumber: Hasil pengolahan data

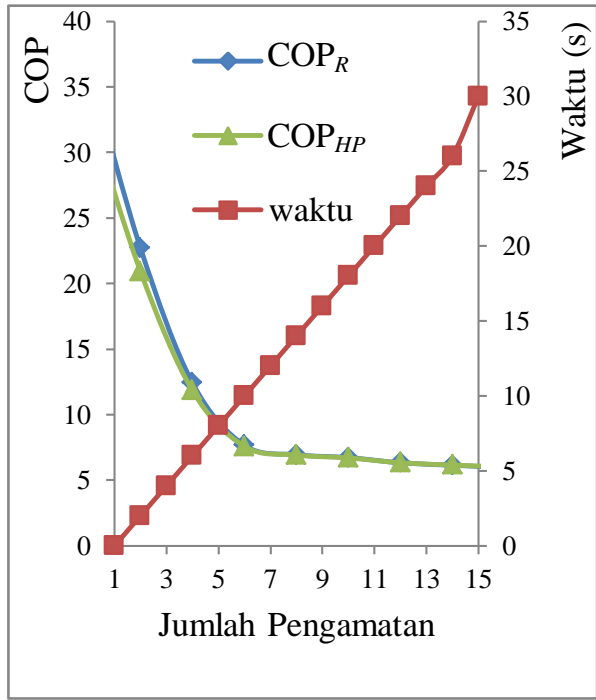

Grafik 5. Perbandingan nilai $\mathrm{COP}_{R}, \mathrm{COP}_{H P}$, terhadap waktu.

Chart 5. $C O P_{R}, C O P_{H P}$, vs time. Sumber: Hasil pengolahan data 


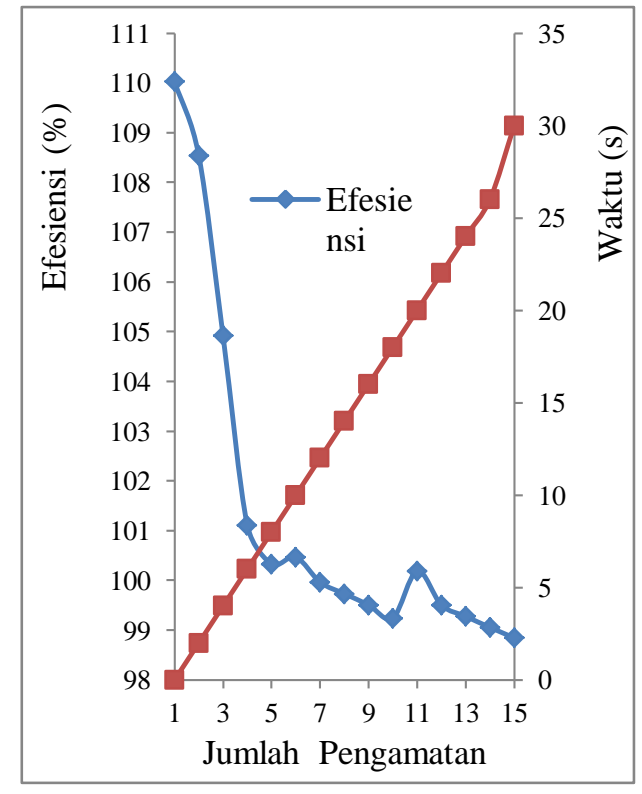

Grafik 6. NIlai efesiensi terhadap waktu.

Chart 6. Efficiency vs time.

Sumber: Hasil pengolahan data

Dari grafik 6 terlihat bahwa nilai efesiensi yang cukup baik berkisar antara 110 dan 98. Nilai efesiensi melebihi $100 \%$ disebabkan karena siklus refrigerasi sistem meja penjaja ikan menganut sistem tertutup. Sistem tertutup adalah fluida kerja dalam satu siklus tidak ada yang terbuang ke udara luar. Sedangkan siklus terbuka dimana fluida keja dari sistem terbuang ke udara seperti pompa dan motor bakar.

Uji kelayakan meja penjaja ikan dengan sistem refrigerasi, dihitung dengan menggunakan persamaan 8 dalam waktu 30 menit, dimana 1 $\mathrm{kWh}=859,9 \mathrm{kkal}$. Diperoleh hasil perhitungan dari kinerja meja penjaja dalam waktu 30 menit, mampu mendinginkan $50 \mathrm{~kg}$ ikan dari suhu ikan $24{ }^{\circ} \mathrm{C}$ ke suhu $-2{ }^{\circ} \mathrm{C}$. Dengan beda temperetur $(\Delta \mathrm{T})$ $26{ }^{\circ} \mathrm{C}$ dan panas spesifik ikan $\left(C_{p}\right) 0,84$, sistem mampu menyerap kalor ikan sebesar 1092 kkal.

\section{KESIMPULAN DAN SARAN}

Dari hasil analisis pengujian sistem refrigerasi meja penjaja ikan, maka dapat disimpulkan bahwa sistem refrigerasi meja penjaja ikan dapat bekerja dengan baik, dimana nilai COP masuk dalam batasan COP SNI dengan nilai efesiensi $99 \%$. Dengan jumlah ikan sebanyak $50 \mathrm{~kg}$ dan daya ratarata sebesar 350 Watt, meja tersebut mampu menyerap kalor ikan sebesar 1092 kkal selama 30 menit dengan temperatur maksimal sebesar $-15^{\circ} \mathrm{C}$.

\section{UCAPAN TERIMA KASIH}

Penulis mengucapkan terima kasih kepada Kepala P3TKP atas terlaksananya kegiatan ini. Tidak lupa kami ucapkan terima kasih pula untuk rekan-rekan peneliti dan teknisi: Daud, Amin, Hadi, Agus, Paino dan Wahyu atas bantuannya dalam instalasi dan pengujian meja penjaja ikan dengan sistem refrigerasi.

\section{DAFTAR PUSTAKA}

Anwar, K. (2010). Efek beban pendinginan terhadap performa sistem pendingin. Jurnal SMARTEK, $8(3), 203-214$.

Chandrasekharan, M. (2014). Exergy analysis of vapor compression refrigeration system using R22 and $\mathrm{R} 134 \mathrm{a}$ as refrigerants. International Journal of Students Research in Technology and Mangement, 2(4), 134- 139.

Daniel, D. (2011). Laporan Akhir Penelitian Palkah Pendingin Tenaga Matahari. P3TKP.

Dossat, R. J. (1961). Principles of Refrigeration. Toppan Company, Tokyo.

Gulati, R., \& Gupta, C. R. (2011). Effect of various parameter on the performance of capillary tube. International Journal of Engineering Science and Technology, 3(8), 6202-6207.

Handoyo, E. A., \& Lukito, A. (2002). Analisis pengaruh pipa kapiler yang dililitkan pada line suction terhadap performansi mesin pendingin. Jurnal Teknik Mesin, 4(2), 94-98.

Ilyas. (1983). Teknologi Refrigerasi Hasil Perikanan Jilid 1 Teknik Pendingin Ikan. Badan Penelitian dan Pengembangan Pertanian. Paripurna: Jakarta.

Irianto, H. E., \& Soesilo, I. (2007). Dukungan Teknologi Penyediaan Produk Perikanan. Makalah Seminar Nasional Hari Pangan Sedunia. Bogor.

Jain, V., Kachhwaha, S. S., \& Mishra, R. S. (2011). Comparative performance study vapour compression refrigeration system with R22, R134a, R410a, R407c and MC20. International Journal of Energy and Environment, 2(2), 297-310.

Pusat Pengembangan dan Pemberdayaan Pendidik dan Tenaga Kependidikan Pertanian. (2010). Mata Diklat. Penanganan dan Penyimpanan Hasil Tangkap.

Raut, A.S., \& Wankhede, S.U. (2011). Selection of capillary tubes for retrofitting in refrigeration

JURNAL KELAUTAN NASIONAL, Vol. 9, No. 3, Desember 2014, Hal. 121-127 
appliances. International Journal of Engineering Science and Technology, 3(1), 705-711.

Sattar, A. M., Saidur, R., \& Masjuki, H. H. (2007). Performance investigation of domestic refrigerator using pure hydrocarbons and blends of hydrocarbons as refrigerants. International Journal of Mechanical Systems Science and Engineering, 1(1), 50-55.

Setyoko, B., Darmanto, S., \& Rahmat. (2007). Analisis mesin pendingin pada kapal ikan. Jurnal Teknik, 28(3), 245-250.

Sjarif, B., Suwardiyono, \& Syahasta, D. G. (2010). Penangkapan dan Penaganan Ikan Tuna Segar di Kapal Rawai Tuna. Balai Besar Pengembangan Penangkapan Ikan. Semarang.

Suherman, M., \& Gunawan, B. (1999). Palka Berinsulasi untuk Penaganan Ikan Segar pada Perahu Motor Nelayan Kepulauan Seribu DKI Jakarta. Lokakarya Fungsional Non Peneliti.

Tampubolon, D., \& Samosir, R. (2005). Pemahaman tentang refrigerasi. Jurnal Teknik SIMETRIKA, 4(1), 312-316.

Tiwari, A., \& Gupta, R. C., (2011). Experimental study of R404a and R134a in domestic refrigerator. International Journal of Engineering Science and Technology, 3(8), 6390- 6393.

Verma, J. K., Satsangi A., \& Chaturani V. (2013). A review of alternative to $\mathrm{R} 134 \mathrm{a}$ (Ch3ch2f) refrigeration. International Journal of Emerging Technology and Advanced Engineering, 3(1), 300-304.

Wibowo, S., \& Yunizal. (1998). Penanganan Ikan Segar. Instalasi Penelitian Laut Slipi. Jakarta.

Yunianto, B. (2005). Pengaruh perubahan temperatur evaporator terhadap prestasi air cooled chiller dengan refrigerant $\mathrm{R} 134 \mathrm{a}$ pada temperature kondensor tetap. Jurnal Rotasi, 7(3), 25-30. 
